\title{
Understanding coherence and integration in integrated STEM curriculum
}

\author{
Gillian H. Roehrig ${ }^{1^{*}}$ (D) Emily A. Dare ${ }^{2}$, Elizabeth Ring-Whalen ${ }^{3}$ and Jeanna R. Wieselmann ${ }^{4}$
}

\begin{abstract}
Background: Few tools or rubrics exist to assess the quality of integrated STEM curricula, and existing tools focus on checklists of characteristics of integrated STEM. While such instruments provide important information about the presence and quality of certain curricular components, they do not assess the level and nature of integration of the curriculum as a whole. Thus, this study explores the development of a process focused to understand the nature of integration within a STEM curriculum unit.

Findings: A conceptual flow graphic (CFG) was constructed for 50 integrated STEM curriculum units. Patterns in the nature of the interdisciplinary connections were used to categorize and understand the nature of integration and curricular coherence within each unit. The units formed four broad types of integrated STEM curricula: (i) coherent science unit with loosely connected engineering design challenge (EDC), (ii) engineering design-focused unit with limited connections to science content, (iii) engineering design unit with science content as context, and (iv) integrated and coherent STEM units. All physical science units were in the integrated and coherent category with strong conceptual integration between the main science concepts and the EDC. Curricula based in the Earth and life sciences generally lacked conceptual integration between the science content and the EDC and relied on the engineering design process to provide a coherent storyline for the unit.

Conclusions: Our study shows that engineering practices can serve as a contextual integrator within a STEM unit. The utilization of an EDC also provides the potential for conceptual integration because engineering is grounded in the application of science and mathematics. Integrated STEM curricula that purposefully include science and mathematics concepts necessary to develop solutions to the EDC engage students in authentic engineering experiences and provide conceptual integration between the disciplines. However, the alignment of grade-level science standards with the EDC can be problematic, particularly in life science and Earth science. The CFG process provides a tool for determining the nature of integration between science and mathematics content and an EDC. These connections can be conceptual and/or contextual, as both forms of integration are appropriate depending on the instructional goals.
\end{abstract}

Keywords: Integrated STEM, Curriculum assessment, Nature of integration

\footnotetext{
* Correspondence: roehr013@umn.edu

${ }^{1}$ STEM Education Center, University of Minnesota, Learning and

Environmental Sciences 320, 1954 Buford Ave, St. Paul, MN 55108, USA

Full list of author information is available at the end of the article
}

\section{Springer Open}

(c) The Author(s). 2021 Open Access This article is licensed under a Creative Commons Attribution 4.0 International License, which permits use, sharing, adaptation, distribution and reproduction in any medium or format, as long as you give appropriate credit to the original author(s) and the source, provide a link to the Creative Commons licence, and indicate if changes were made. The images or other third party material in this article are included in the article's Creative Commons licence, unless indicated otherwise in a credit line to the material. If material is not included in the article's Creative Commons licence and your intended use is not permitted by statutory regulation or exceeds the permitted use, you will need to obtain permission directly from the copyright holder. To view a copy of this licence, visit http://creativecommons.org/licenses/by/4.0/. 


\section{Background}

National policy documents in the USA calling for improvements to K-12 STEM Education have been prevalent in the past decade. Within the USA, Rising Above the Gathering Storm (National Academy of Science, National Academy of Engineering, and Institute of Medicine, 2007) advocated for a federal effort to prepare more students for STEM careers. Such calls were in response to the argument that the continued prosperity and progress in the global marketplace depended on the education community's ability to prepare the future generation of STEM professionals (National Academy of Science, National Academy of Engineering, and Institute of Medicine, 2007; Toulmin \& Groome, 2007). These calls culminated in the Framework for K-12 Science Education (National Research Council, 2012) and the Next Generation Science Standards (NGSS Lead States, 2013) that put forth new national standards in which engineering, technology, and mathematical thinking were purposefully and explicitly integrated into K-12 science education, which has resulted in the rise of integrated STEM education.

In the USA, new curricula have long been considered central to science education reforms (Powell \& Anderson, 2002). However, within the USA, there is no national curriculum to move forward reform initiatives such as the NGSS. Instead, education is decentralized, with decisions about curriculum and instruction left to states and local school districts. Educational reform efforts have posited that curriculum frameworks can be used as "guides that state and local officials might use in developing curricula for local use" (National Science Board, Commission on Precollege Education in Mathematics, Science and Technology, 1983, p. 41). In the past, federally funded curriculum development efforts related to the National Science Education Standards (NSES; National Research Council, 1996) were problematic, as alignment to NSES was interpreted broadly and curriculum writing approaches varied widely (DeBoer, 2014). These concerns extend to the NGSS (NGSS Lead States, 2013), which includes performance expectations that describe what students should understand and how they should apply a particular practice within content-driven contexts (NGSS Lead States, 2013). As with the NSES (National Research Council, 1996), no explicit curriculum guidelines or frameworks are provided through policy documents as to how to meet the expectations of the NGSS. Consequently, a broad set of definitions of STEM exist within the field (Bybee, 2013), which has led to a multitude of new STEM and engineering curricula of varied quality and degrees of alignment to research-based characteristics of integrated STEM education (Bybee, 2013; Moore, Stohlmann, Wang, Tank, \& Roehrig, 2014; National Academy of Engineering and National Research Council, 2009). Thus, there is an urgent need to create tools that can assess the alignment of these myriad STEM curriculum units with the goals and tenets of integrated STEM approaches to teaching and learning. Few tools or rubrics exist to assess the quality of written integrated STEM curricula, and existing tools such as the STEM Integration Curriculum Assessment (STEM-ICA; Guzey, Moore, \& Harwell, 2016; Walker, Guzey, Moore, \& Sorge, 2018) focus on the presence of the individual disciplines and checklists of characteristics of integrated STEM education. While instruments such as the STEM-ICA provide important information about the presence and quality of certain curricular components, they do not assess the level and nature of integration of the curriculum as a whole. This paper explores the development of a curriculum assessment process focused on the nature of integration within a STEM curriculum unit.

\section{Literature review}

\section{Real-world problems and curriculum integration}

The problems we face in the world are complex and require the integration of multiple disciplines, concepts, and skills to solve them. It is the multidisciplinary nature of real-world problems, as opposed to the disciplinary structure within formal schooling, that grounds arguments for curricular integration (Beane, 1995; Czerniak, Weber, Sandmann, \& Ahern, 1999; Jacobs, 1989). Meaningful learning can occur when learners make connections between prior knowledge and new experiences and skills within real-world contexts (Brooks \& Brooks, 1993). Indeed, Hirst (1974) argued that the artificial separation of subject areas restricts learning by alienating learners from real-world experiences. Specific to integrated STEM, researchers agree that integrated STEM instruction should use real-world contexts to engage students in authentic and meaningful learning (Kelley \& Knowles, 2016; Moore, Stohlmann, et al., 2014; Sanders, 2009) because teaching in silos "does not reflect the natural interconnectedness of the four STEM components in the real world of research and technology development" (National Research Council, 2009 , p. 150). However, curricular integration is complex and requires more than simply putting different subject areas together in a lesson or unit in relation to a theme or real-world problem.

\section{Approaches to curriculum integration}

Drake $(1991,1998)$ described curriculum integration through multidisciplinary, interdisciplinary, and transdisciplinary approaches while making it clear that "one position is not superior to another; rather, different approaches are more appropriate than others according to the context in which they are used" (Drake, 1998, p. 19). Multidisciplinary approaches often use a theme or real-world issue to make the connections among subject 
areas. In a multidisciplinary approach, each discipline would be identifiable within the curriculum (Lederman \& Niess, 1997). This approach could take place in a single classroom or through curricular alignment across multiple subject area classes (Drake, 1998; Fogarty, 1991). In interdisciplinary approaches, the subjects are interconnected beyond a theme or issue, cut across subject areas, and focus on interdisciplinary content and skills. As such, each discipline would be difficult to distinguish from one another (Lederman \& Niess, 1997). Transdisciplinary approaches use real-world issues to connect social, political, economic, international, and environmental concerns; the focus is on real-world problems, not different subject areas. Parallel to the curricular integration literature, integrated STEM has been categorized from disciplinary to transdisciplinary approaches (e.g., Bybee, 2013; Honey, Pearson, \& Schweingruber, 2014; Moore \& Smith, 2014; Vasquez, Sneider, \& Comer, 2013). Vasquez et al. (2013) define a continuum of increasing integration from disciplinary to transdisciplinary (see Table 1).

\section{Curriculum integration within the STEM disciplines}

Historically, research has attended to the integration of science and mathematics (e.g., Berlin \& White, 1995; Davison, Miller, \& Metheny, 1995; Huntley, 1998) with little attention to technology and engineering (Bybee, 2010; Hoachlander \& Yanofsky, 2011). However, the recent addition of engineering concepts and practices to state and national science standards (National Research Council, 2012; NGSS Lead States, 2013) has expanded consideration of integration beyond the disciplines of science and mathematics. The addition of engineering standards into the NGSS and state standards has led to a renewed focus on integration because engaging students in engineering design requires an interdisciplinary approach that incorporates knowledge from science, mathematics, and technology (Brophy, Klein, Portsmore, \& Rogers, 2008; Douglas, Iversen, \& Kalyandurg, 2004).

Table 1 Levels of STEM integration, adapted from Vasquez et al. (2013)

\begin{tabular}{ll}
\hline $\begin{array}{l}\text { Type of } \\
\text { integration }\end{array}$ & General description \\
\hline Disciplinary & $\begin{array}{l}\text { Content learned in separate disciplinary classrooms } \\
\text { Content learned separately but connected through a } \\
\text { common theme }\end{array}$ \\
Interdisciplinary & $\begin{array}{l}\text { Focus on interdisciplinary content and practices from } \\
\text { two or more disciplines connected through a } \\
\text { common theme or problem }\end{array}$ \\
Transdisciplinary & $\begin{array}{l}\text { Content from two or more disciplines are applied to } \\
\text { real-world problems, with the learning focus on the } \\
\text { real-world problem }\end{array}$ \\
\hline
\end{tabular}

It is important to note that it is not the number of disciplines being integrated that reflects the degree of integration in a STEM curriculum. Rather, it is the connections of the relevant disciplines to the real-world problem and the connections between the disciplines that are important (e.g., Kelley \& Knowles, 2016; Moore, Stohlmann, et al., 2014; Sanders, 2009). For example, Moore, Stohlmann, et al. (2014) broadly defined integrated STEM education as "an effort to combine some or all of the four disciplines of science, technology, engineering, and mathematics into one class, unit, or lesson that is based on connections between the subjects and real-world problems" (p. 38). Similarly, Kelley and Knowles (2016) defined integrated STEM education as "the approach to teaching the STEM content of two or more STEM domains, bound by STEM practices within an authentic context for the purpose of connecting these subjects to enhance student learning" (p. 3). However, both Kelley and Knowles (2016) and Moore, Stohlmann, et al. (2014) emphasize engineering as one of the disciplines; engineering requires the use of science and mathematics to address real-world problems (Sheppard, Macantangay, Colby, \& Sullivan, 2009) and thus, engineering design can "provide the ideal STEM content integrator" (Kelley \& Knowles, 2016, p. 5). Given the prominence of engineering within STEM policy documents (e.g., National Research Council, 2011, 2012; NGSS Lead States, 2013), an engineering context or problem is considered as central to integrated STEM curriculum (Bryan, Moore, Johnston, \& Roehrig, 2015; Hmelo, Douglas, \& Kolodner, 2000; Mehalik, Doppelt, \& Schunn, 2008; Moore, Glancy, Tank, Kersten, \& Smith, 2014; Sadler, Coyle, \& Schwartz, 2000).

Engineering is characterized by engineering design processes (Dym, 1999), and engaging students in the engineering design process (EDP) is a central component of both undergraduate (Accreditation Board for Engineering and Technology [ABET], 2019) and K-12 STEM education (Moore, Tank, Glancy, \& Kersten, 2015). Engineering is defined in K-12 settings as an "iterative process that begins with the identification of a problem and ends with a solution that takes into account the identified constraints and meets specifications for desired performance" (National Academy of Engineering, 2010, p. 6-7). Within the Framework (National Research Council, 2012) and the NGSS (NGSS Lead States, 2013), engineering is broadly described through the eight science and engineering practices, as well as three disciplinary core ideas (DCIs): (i) defining and delimiting an engineering problem, (ii) developing possible solutions, and (iii) optimizing design solutions. Cunningham and Carlsen (2014) argue that these DCIs are mislabeled as core concepts, as the wording better reflects engineering practices. With this in mind, it is clear that the priority of the NGSS is on engaging students in engineering practices, not necessarily learning engineering concepts. 
Despite engineering requiring the application of science and mathematics concepts, researchers argue that helping students understand the connections between the disciplines is not easy (English, 2016; Honey et al., 2014; Moore, Glancy, et al., 2014). The interrelationships among the disciplines are complex and require teaching STEM content in deliberate and purposeful ways so that students understand how STEM knowledge is conceptually linked. Curriculum units or real-world problems may have implicit connections between the disciplines themselves and between the disciplines and the real-world problem. However, it is not enough to assume that students will make these connections; these relationships between the disciplines must be made explicit for students (Kelley \& Knowles, 2016; Moore, Glancy, et al., 2014; National Research Council, 2009).

\section{Conceptual frameworks for the evaluation of integrated STEM curricula}

Curriculum development requires a move from broad conceptualizations of STEM education to specific frameworks that guide curricular decisions. Our work draws on two complementary frameworks from the integrated STEM literature. The first framework for integrated STEM (Moore, Stohlmann, et al., 2014) argues that a quality integrated STEM curriculum includes six tenets: (a) a motivating and engaging context, (b) an engineering design challenge, (c) the opportunity to learn from failure through redesign, (d) math and/or science content, (e) student-centered pedagogies, and (f) an emphasis on teamwork and communication. Given the centrality of an engineering design challenge (EDC) within integrated STEM curricula, the second framework is the Framework for Quality K-12 Engineering Education (Moore, Glancy, et al., 2014), which was designed to be used as a tool for evaluating the degree to which academic standards, curricula, and teaching practices address key components of a quality K-12 engineering education. This framework consists of nine indicators: (a) process of design, (b) apply SEM knowledge, (c) engineering thinking, (d) conceptions of engineers and engineering, (e) engineering tools and processes, (f) issues, solutions, and impacts, (g) ethics, (h) teamwork, and (i) communication related to engineering.

Guzey et al. (2016) used these frameworks to develop the STEM Integration Curriculum Assessment (STEMICA), which consists of nine items, each scored on a 0-4 scale: (a) motivating and engaging context, (b) engineering design, (c) integration of science content, (d) integration of mathematics content, (e) instructional strategies, (f) teamwork, (g) communication, (h) assessment, and (i) organization. These nine items are structured as a checklist of sorts to indicate the extent to which key indicators are present within a curriculum unit. In terms of integration, two of the nine items assess the extent to which the curriculum integrated science or mathematics content needed to solve a central EDC to support students' in-depth understanding (item c: to what extent does the curriculum unit integrate science content that is needed to solve the engineering challenge and support in-depth understanding? and item d: to what extent does the curriculum unit integrate mathematics content that is needed to solve the engineering challenge and support in-depth understanding?). In their analysis of 20 integrated STEM curriculum units, Guzey et al. (2016) reported that the integration of science and mathematics content was weak based on scores for the science and mathematics integration items; however, no qualitative details are provided about the nature of integration suggesting that further investigation into the nature of integration in STEM units is needed.

\section{Assessment of curricular coherence in STEM curricula}

Missing from the STEM-ICA is explicit consideration of the curricular coherence of an integrated STEM unithow concepts are sequenced and linked to one another, both within and across lessons. Beane (1995) defines a coherent curriculum as "one that holds together, that makes sense as a whole, and its parts, whatever they are, are unified and connected by that sense of the whole" (p. $3)$. Coherence occurs across different time scales; for example, connections are made from 1 year to the next, from one topic or unit to the next, from one lesson to the next within a unit, and from one statement to the next within a lesson. This coherence of ideas is particularly important because research suggests that unrelated ideas are less meaningful than those that are richly interrelated, and as such, learning is impacted by the coherence of ideas (Chi, Glaser, \& Rees, 1982; Resnick, 1987). The video study of science teaching in the Trends in International Mathematics and Science Study (TIMSS) revealed two issues with coherence in science lessons in the USA (Roth et al., 2006). First, lessons rarely supported students in developing explanations and conceptual understanding from science activities. Second, content was often presented as "isolated bits of information without being linked to a larger concept" (Roth et al., 2006, p. 61). This lack of coherence in science curricula has been identified as a critical issue for student learning (Mintzes, Wandersee, \& Novak, 2000; Monk \& Osborne, 2000; Roth et al., 2006), and integrated STEM curricula may help to address this concern.

Given that integrated STEM curricular units aim to engage students in problem-based learning through engineering design tasks (Harwell et al., 2015; Hmelo et al., 2000; Mehalik et al., 2008; Moore, Glancy, et al., 2014; Sadler et al., 2000) which, in turn, facilitates 
students' learning of STEM concepts and their application to solve real-world problems (Guzey, Harwell, Moreno, Peralta, \& Moore, 2017; Han, Capraro, \& Capraro, 2015; Siregar, Rosli, Maat, \& Capraro, 2020), curricular coherence is an important consideration in determining the quality of integrated STEM curriculum (Guzey et al., 2016). Not only do connections between the STEM disciplines and to the real-world context need to be clear and explicit (English, 2016; Honey et al., 2014; Moore, Glancy, et al., 2014), these connections also need to develop concepts through a coherent curricular storyline within a unit (Beane, 1995; Roth et al., 2006).

It is also noteworthy that throughout the integrated STEM literature, science is often treated as a singular discipline without consideration of distinct subdisciplines such as physics, chemistry, and biology (e.g., Kelley \& Knowles, 2016; Moore, Stohlmann, et al., 2014). Several researchers argue that integrating engineering into physical science is relatively easy, as physics concepts are readily applicable to many mechanical, electrical, and civil engineering contexts (Dare, Ellis, \& Roehrig, 2014; Guzey et al., 2016). In contrast, "life science concepts are abstract and design activities in life science classes often require the use of technologies that are not commonly found in K-12 classrooms" (Guzey et al., 2016, p. 3); thus, engineering lessons within the life and Earth sciences are less common (Cira et al., 2015; Dare et al., 2014). However, almost no research compares curriculum development and implementation across the science disciplines. Guzey et al. (2016) compared K-12 Earth science, life sciences, and physical science STEM units and found that physical science units had significantly higher scores for the inclusion of a motivating and engaging context. In addition, they reported that the majority of the curricula with the highest scores for science integration were in the physical sciences. Other studies suggest that STEM integration is problematic in $\mathrm{K}-12$ life science classrooms and that most K-12 life science STEM curricula use life science as a context rather than content to be applied in developing design decisions (Guzey, Ring-Whalen, Harwell, \& Peralta, 2019; Roehrig \& Dewey, 2021). Thus, this study presents an assessment process to evaluate the nature of disciplinary integration and the degree of coherence within integrated STEM curricula within the K-12 Earth, life, and physical sciences.

\section{Research questions}

1. How can the nature of integration and curricular coherence in integrated STEM curricula be represented and categorized?
2. How does the nature of integration and curricular coherence differ based on content-focus of integrated STEM curricula (Earth, life, and physical sciences)?

\section{Methodology}

Context

EngrTEAMS (Engineering to Transform the Education of Analysis, Measurement, and Science) was an \$8 million Mathematics and Science Partnership grant specifically designed to address the professional development (PD) needs of in-service STEM teachers (grades 3-9) to promote the development of integrated STEM learning environments and curricular units. During the first three summers, EngrTEAMS provided 3 weeks of extensive teacher PD focused on learning about engineering and using engineering design tasks to support $\mathrm{K}-12$ students' learning in science and mathematics, specifically data analysis and measurement. Each of the authors worked for at least 2 years on the project in the role of PD provider and/or graduate student coach. Teacher participants were recruited from five partner districts within the metropolitan area in which the PD was offered, including two urban, two first-ring suburban, and one suburban district. Table 2 provides an overview of teacher participants across the first 3 years of the project. All of the teachers were responsible for teaching science, as either a certified secondary science teacher, elementary science or STEM specialist, or elementary teacher. An approved IRB covered the entire EngrTEAMS PD, and all participants consented for data collection related to larger studies, including analysis of their curriculum materials, which is the focus of this study.

During the summer PD, teams of teachers developed new integrated STEM units for use in their science classrooms with the support of a graduate student coach. Graduate student coaches had prior K-12 teaching experience and expertise in integrated STEM education. The teachers' curriculum writing was guided by the state's science standards, which included engineering

Table 2 Teacher participants by year

\begin{tabular}{llll}
\hline & Year 1 & Year 2 & Year 3 \\
\hline Total & 47 & 42 & 44 \\
Urban A & 26 & 19 & 11 \\
Urban B & 12 & 8 & 17 \\
First-ring suburban A & & 6 & 4 \\
First-ring suburban B & 9 & 9 & 4 \\
Suburban & & 14 & 8 \\
Returners from previous year & & & $20^{\mathrm{b}}$ \\
\hline
\end{tabular}

${ }^{a}$ Returning teachers developed and piloted new STEM curriculum units each year

${ }^{\mathrm{b}} 10$ teachers attend the PD all 3 years 
design, and was supported by two frameworks for STEM integration that centralized the role of the EDP to solve a real-world problem (Moore, Glancy, et al., 2014; Moore, Stohlmann, et al., 2014). They were also guided to use a client letter (either fictitious or authentic) to introduce and contextualize a central engineering problem or design challenge and solicit students' help in solving it while adhering to certain criteria and constraints. While teachers were expected to develop an integrated STEM curriculum that included an EDC and aligned with the STEM frameworks presented during the PD, they were given freedom to decide on other details such as the length of the unit and how to include the new unit into their existing scope and sequence for science.

Teachers piloted their team's curriculum in a university summer camp and used this experience to revise their curriculum before implementing the unit in their respective classrooms during the academic year. Each teacher team also scored their curriculum using the STEM-ICA (Guzey et al., 2016) to provide additional evidence for curricular revisions, including items related to coherence and integration. With support of the graduate student coach, final revisions to the integrated STEM unit were made before the end of the academic year (for more details, see McFadden \& Roehrig, 2020; Ring, Dare, Crotty, \& Roehrig, 2017). This PD and iterative curriculum design process was repeated for 3 years, leading to a total of 50 unique integrated STEM curriculum units. The focus of this study is on the nature of these final STEM curriculum units, not the iterative changes made to curricula by the teacher teams.

\section{Research design}

This study employed a multiple case study design (Yin, 2014) contextualized within the EngTEAMS PD. A case study method was selected to provide an in-depth description and exploration of the phenomenon of integrated STEM curricula (Yin, 2014). The use of multiple cases allows for an understanding of the differences and the similarities between the cases (Stake, 1995). While each team of teachers experienced the same PD and introduction to integrated STEM frameworks, it was necessary for them to consider the unique context of their science topic, grade level, and student population. Thus, the individual cases were the 50 integrated STEM curriculum units developed by teams of EngrTEAMS teachers and their coaches across the first 3 years of the program.

\section{Data collection and visualization of the STEM curricula}

Visual representations of each of the final written versions of the 50 written curricula were created by generating a conceptual flow graphic (CFG) for each individual curriculum. CFGs are one of a suite of tools that are part of the analyzing instructional materials (AIM) process (Bintz, 2009). AIM provides a process and a set of tools for evaluating and selecting science curricula. Specifically, at the unit level, we focused on the CFG, which represents a process that evaluates a curriculum at the macro level for the alignment of individual lessons to the main learning goals and coherence (or storyline) between lessons. This analytic tool aligns with the conceptual frameworks for integrated STEM that call for explicit integration of science, engineering, and mathematics concepts and practices and application of these concepts and practices to a central EDC (Moore, Glancy, et al., 2014; Moore, Stohlmann, et al., 2014).

The CFG includes the main concept(s) addressed within each lesson, arranged chronologically, and connected by arrows that represent the strength of the connections among the concepts and the main learning goal; a unit that shows strong connections between lessons and between each lesson and the central learning goal looks similar to a bicycle wheel with spokes. The steps to create a CFG are described below using one of the STEM curriculum units, Museum Security, as an illustrative example. Museum Security was designed for a sixth-grade physical science class to develop students' knowledge of light reflection and refraction.

To create a CFG, the central goal or performance expectation for the unit is first identified. The language of the NGSS is purposefully used here; performance expectations are not a set of daily standards or learning goals, rather they are statements of what students should be able to do by the end of an instructional unit. For the integrated STEM curricula in EngrTEAMS, the performance expectation for each curriculum unit was associated with developing solutions for a real-world problem or EDC. For example, in the Museum Security curriculum, the performance expectation is to design a laser security system to protect the artifacts in a traveling museum exhibit. The following excerpt from the client letter provides more details about the EDC that is the focus of the unit:

You will need to draw on your scientific knowledge to create a laser security system using light from a single laser. Each host city might choose a different layout for the artifacts, and the security system will be for the entrance room to the museum that contains the key artifacts from the collection. You will need to decide with your team how many artifacts to display in the entrance room and where to place the artifacts in relation to your security system. Your design must ensure that a thief will need to cross the laser light at least three times from where they enter the room to where they reach the artifacts. The laser security system must be complicated enough to deter thieves from attempting to steal the artifacts. Therefore, the laser light must refract at least one time and reflect at least one time. 
Second, the main concepts to be learned in each lesson are determined. While there may be possible subconcepts within a lesson, the goal is to identify the central concepts. For the purpose of an integrated STEM lesson, these concepts were labeled as science, engineering, or mathematics. Following the analysis of engineering within the NGSS by Cunningham and Carlsen (2014), engineering was represented in the analysis using the central engineering practices within a lesson. Reynante, Selbach-Allen, and Pimentel (2020) note that it is sometimes difficult to distinguish between science and mathematics in K-12 science classrooms where applied mathematics rather than pure mathematics is most often present. This was the case in the integrated STEM curricula analyzed in this study, as mathematics was often present in a lesson as a tool in the service of science or engineering (e.g., graphing, calculating averages) rather than as a main concept to be learned. As the CFG process described by Bintz (2009) only includes main concepts, this could lead to visualizations that were not representative of the ways in which mathematics is present in integrated STEM curricula. Thus, the presence of mathematics as a tool is marked in the CFG with the annotation MaT next to the relevant lesson (not present in the analysis of the Museum Security curriculum). Technology was treated in the STEM PD, and consequently within the teacher-developed curricula, as the product of engineering. Teachers also explicitly considered technology integration from a pedagogical view within their curricula (e.g., SmartBoard, videos, etc.). From either perspective, technology was not represented as concepts within the curricula.

Third, connections between each lesson's content and the central learning goal (client letter) are identified. References to the client within some of the curriculum units represent an important connection to the EDC and a possible vehicle for curricular coherence. Thus, references to the client were included in the analysis in two ways. The first was through explicit connections using curriculum materials such as a client letter, memo, or email. The second was through pedagogical connections provided in the teacher guidelines that accompanied each curriculum unit. For example, the teacher guide might direct teachers to remind the students about the EDC and the needs of the client at the start of a lesson. Table 3 illustrates the results of steps two and three for the Museum Security unit.

Once the central performance expectation, main concept(s) from each lesson, and connection to the client have been identified, the visual representation of the unit is created. At the center of the CFG is the performance expectation for the unit, surrounded by the main concept(s) for each lesson, arranged chronologically. Lessons with identical main concepts are combined at this stage (in the case of Museum Security, Lessons 5 and 6 address the same main learning concepts in science and mathematics). The depth of conceptual connection between each lesson and the main unit goal, as well as the depth of conceptual connections from one lesson to the next, are determined. Strong conceptual connections (those that demonstrated direct or explicit building on conceptual knowledge) are designated with a full arrow; weak conceptual connections (those with limited or implied connections) are designated with a dotted arrow, and the absence of an arrow indicates that there is no conceptual link. For example, Lesson 3 includes two main concepts: (i) light travels in straight lines and (ii) light interacts differently (absorption and transmission) with different surfaces. Understanding that light travels in straight lines is necessary to be able to develop an understanding about the law of reflection, which is the main concept within Lesson 4; thus, this is indicated as a strong conceptual link with a solid arrow. However, an understanding of light absorption and transmission with different surfaces is not directly necessary to develop an understanding of the law of reflection; thus, this is marked as a weak conceptual link with a dotted arrow. Similarly, developing a prototype for the museum security system requires an understanding that light travels in straight lines and the law of reflection; as a result, links from these lesson concepts to the central performance expectation are shown as strong links with solid arrows. However, since students are provided with mirrors and lenses for their designs, it is not necessary to understand how different surfaces absorb and transmit light; this concept is not conceptually linked to the central performance expectation, and no arrow is included.

Contextual connections between science or mathematics content within a lesson and the main unit goal are shown with a dashed arrow (not present in the analysis of the Museum Security curriculum). Contextual connections to the client are shown through boxes around the main concepts for each lesson. Direct contextual connections through curriculum materials, such as client letters, memos, and emails, are designated with a bold black box around the lesson concepts. Pedagogical connections through teacher guidelines that direct the teacher to remind students about the EDC and the client's needs are designated with a dashed black box around the lesson concepts. The CFG for the Museum Security curriculum is shown in Fig. 1.

As can be seen in Fig. 1, links between lessons and links between the lessons and the main unit goal in the Museum Security curriculum are generally present; however, this is not always the case. For example, while Lesson 2 includes content related to wave properties from the state science standards for middle school physical science, the content is not necessary for 
Table 3 Museum security lessons and main concepts

\begin{tabular}{ll}
\hline Lesson & Main concepts to be learned \\
\hline Lesson 1 & $\begin{array}{l}\text { Engineering } \\
\text { Engineers use the engineering design } \\
\text { process (EDP) to develop solutions. } \\
\text { Engineering solutions have to meet the } \\
\text { needs of a client. }\end{array}$ \\
Lesson 2 & $\begin{array}{l}\text { Science } \\
\text { Waves can be characterized by their } \\
\text { wavelength, amplitude, and frequency. } \\
\text { The color of light is related to wave } \\
\text { properties. }\end{array}$ \\
& \\
& \\
& \\
& Science \\
& Light travels in straight lines. \\
Light interacts differently (absorption and \\
transmission) with different surfaces.
\end{tabular}

\section{Lesson 4 Science}

Light reflects from a mirrored surface. Light reflects and refracts from a lens.

\section{Lesson 5 Science}

The angle of incidence is equal to the angle of reflection.

The angle of refraction is dependent on the material and shape of the lens.

\section{Mathematics}

Measure angles in whole-number degrees using a protractor.

\section{Lesson 6 Science}

The angle of incidence is equal to the angle of reflection.

The angle of refraction is dependent on the material and shape of the lens.

\section{Mathematics}

Measure angles in whole-number degrees using a protractor.

\section{Lesson 7 Engineering}

Engineers iteratively test prototypes to improve their design solution. Engineers use their knowledge of science and mathematics to propose design solutions.

\section{Lesson $8 \quad$ Engineering}

Engineering design solutions must meet the criteria and constraints from the client.

\section{Lesson summary}

Students work in small teams to review the EDP. Students learn about the criteria and constraints of the EDC from a client letter.

Students learn about the wavelength, amplitude, and frequency of waves and how these relate to the energy of the wave. They discuss the color spectrum and relationships between the wave properties and the color of light seen.

Students explore some of the basic properties of light. They observe that light travels in a straight line, spreads out as it moves away from its source, and interacts differently with different surfaces. Students explore absorption and transmission of light using different materials.

Through hands-on activities, students are introduced to reflection and refraction of light. They observe light as it interacts with mirrors and lenses. They learn that light behaves differently depending on the medium with which it is interacting.

Students complete a guided exploration of a simulation. By manipulating variables within the simulation, they discover the law of reflection. They also learn that the angle of refraction is dependent upon the medium through which light is passing, which affects the speed of the light.

Students apply their learning from the simulation to a hands-on activity. Students measure angles of reflection and refraction of different mirrors and lenses.

Based on their knowledge of the behavior of light, students individually brainstorm potential design ideas, then work as a team to determine the best solution to prototype. Students make a physical prototype of their laser security system and iteratively test their proposed laser security system using the design criteria and constraints from the client.

Students use data from the previous lesson to redesign their laser security system. Students compose letters to the client to justify how their design fulfills the criteria and constraints.

\section{Connections to the client}

Students read a client letter that introduces them to the context of their engineering design challenge.

Remind students of the client letter introduced yesterday.

Suggested questions: What do you remember about the client's problem criteria, and constraints?

What scientific knowledge do you think you will need to design a laser security system?

Develop questions for the client. Students should be provided with an opportunity to ask clarifying questions from the client.

Situate learning in engineering design context by reminding students that they need to keep learning about light so they can design a security system.

Students read an email from the client with responses to their questions
Refer students back to the client letter. Suggested questions: What problem are we trying to solve with our designs? How will you know if your design is successful? What constraints or limits will affect how you create your design?

Students compose letters to the client to justify why their design fulfills the criteria and constraints. students to design solutions for a museum laser security system or to engage in the science content learning in subsequent lessons. Students do not need knowledge about the characteristics of waves to design a laser security system, and thus, Lesson 2 represents a break in the conceptual flow of the unit. 


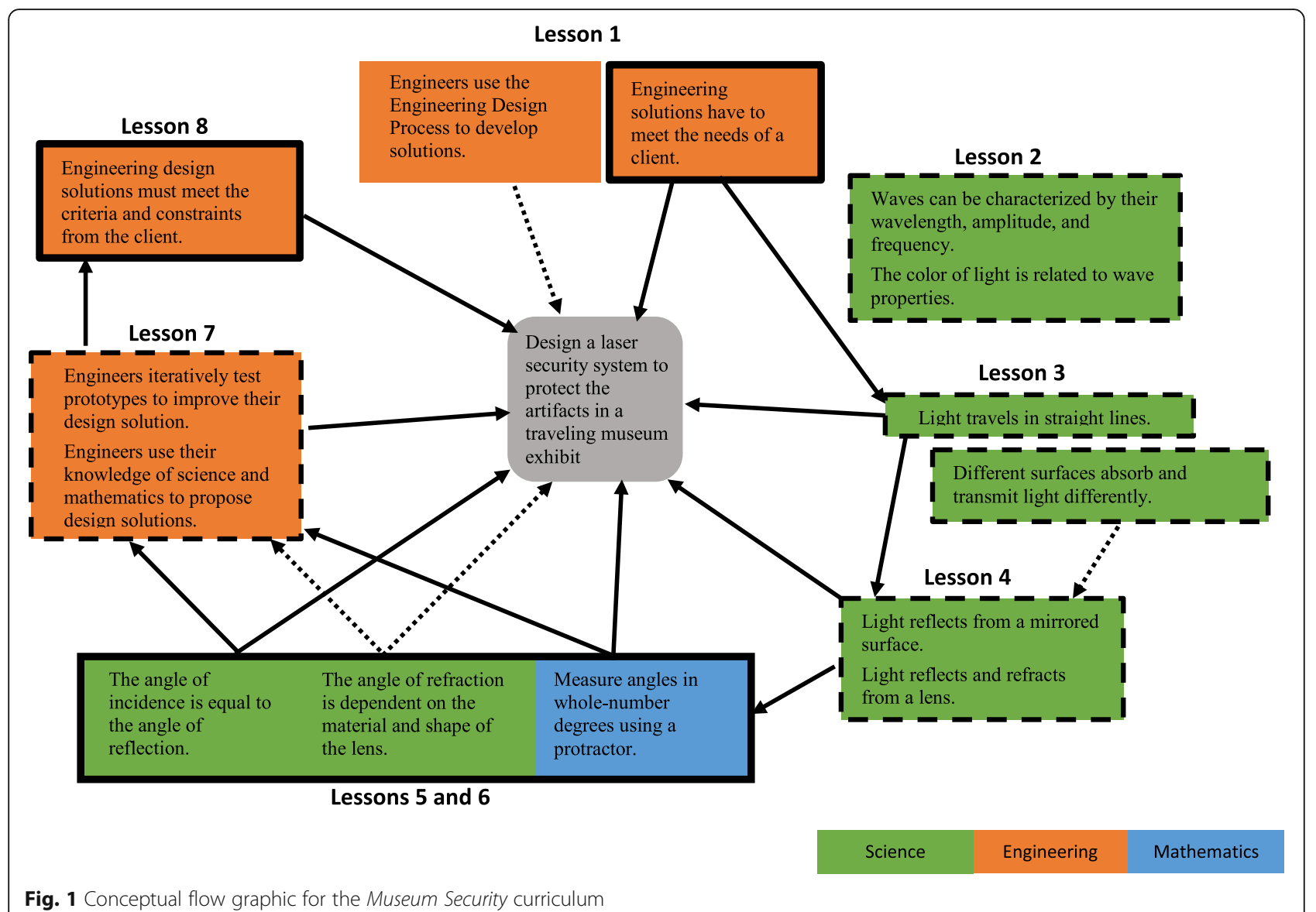

Fig. 1 Conceptual flow graphic for the Museum Security curriculum

\section{Data analysis}

A CFG was constructed for each of the 50 EngrTEAMS curriculum units, following the process described in the previous section. The initial CFG process was developed and refined by three of the authors using three different STEM curricula. The remaining CFGs were created by teams of STEM education graduate students following training on creating CFGs. Each STEM curriculum unit was assigned to two individual students who independently created CFGs, then discussed any differences in their CFGs together with the first author to create a final CFG.

The CFGs were analyzed using a combination of the visual data analysis approach outlined by Cohen, Manion, and Morrison (2011) and inductive coding techniques outlined by Corbin and Strauss (2015). Cohen et al. (2011) suggested that inductive coding can be used in analyzing images. In this study, we utilized open and axial coding (Corbin \& Strauss, 2015) to categorize the CFGs into core categories. Iterative visual analysis was used to inductively sort the CFGs into groups by first looking for patterns with respect to the placement of science, engineering, and mathematics concepts in the lesson sequence. This was followed by considering the conceptual and contextual connections between lessons and from the individual lessons to the central performance expectation. For example, patterns in the placement of engineering lessons allowed two groups to emerge: (i) engineering-focused lessons at the beginning and end of the unit only and (ii) engineeringfocused lessons throughout the unit. Further inductive coding of the larger group of curricula with engineeringfocused lessons throughout the unit revealed differences in the nature of the interdisciplinary connections between science- and engineering-focused lessons. This led to the categorization of engineering-focused units related to the preponderance or lack of conceptual links between science- and engineering-focused lessons. Another iteration of visual coding considered the presence of contextual links to further categorize the curricula.

\section{Results}

The CFGs for the 50 curricula analyzed showed a range of levels and quality of integration as indicated by conceptual coherence. Eight curricular units (one physical science, four life science, and three Earth science) resulted in CFGs with completely disconnected lessons and are not included in the results. The remaining 42 
STEM units formed four broad types of STEM curricula, including (i) coherent science unit with a loosely connected EDC, (ii) engineering design-focused unit with limited connections to science content, (iii) engineering design unit with science content as context, and (iv) integrated and coherent STEM unit (see Table 4). Each of these curricular types is illustrated and discussed in the following sections using an example STEM unit.

\section{Coherent science unit with a loosely connected EDC}

This curricular type included STEM units with an EDC serving to bookend an existing science unit. Typically, the first lesson introduced a real-world problem with an associated EDC. However, the EDC was not addressed again until the final lesson of the unit. While the EDC was topically connected to the science content of the unit, the EDC did not guide decisions about what content to teach, resulting in the majority of science lessons having no conceptual connection to the EDC.

This curricular type is illustrated by the example unit GMO Corn, a 7th grade STEM unit intended for implementation in a life science classroom. At the outset of the unit, students are introduced to genetically modified organisms (GMOs), and the client, an Agricultural Extension Office, has been asked to design a barrier to effectively reduce cross-contamination of non-GMO corn fields with GMO corn fields. The lessons that follow (Lessons 2-5), draw from a life science genetics/heredity curriculum and introduce grade-level standards related to the structure and function of DNA, how phenotypes are expressed and passed down to offspring, etc. In Lesson 6, the focus of the unit returns to GMOs with a lesson on gene splicing and how GMOs are created. In Lessons 7 and 8, the students develop and build a scale model of a solution to prevent cross-pollination of nonGMO corn with GMO corn. Designs for the EDC are evaluated on the extent to which the solutions meet the design specifications. Students write a final letter, including evidence-based reasoning justifying their design decisions, to pitch their design to the client.

The CFG for the GMO Corn curriculum (Fig. 2) shows that while the genetics concepts are conceptually connected to each other (Lessons 2-5); they are, at best, weakly connected to the problem of building a barrier to prevent cross-pollination between non-GMO and GMO corn. The students do not need to apply knowledge of genetics to design a solution to the client's problem; for instance, the design challenge could be met by simply proposing a wall or net as a mechanism to prevent pollen from crossing from one field to another. Typical of all CFGs in this category, while there is an EDC introduced at the beginning of the unit, the engineering design is essentially a culminating project added to the end of an existing science unit, and the science content in the unit is not needed to propose possible design solutions.

\section{Engineering design-focused unit with limited connections to science content}

This curricular type included STEM units that used the EDP as the structure or storyline for the unit. Typically, Lesson 1 included an introduction to the EDC followed by problem scoping and understanding the design criteria and constraints. Lessons then moved through the planning, iterative testing, and final decision and communication phases of the EDP. Science-focused lessons were interspersed throughout the units, but rarely did they provide conceptual or contextual links to inform design decisions. This curricular type is illustrated by the example unit; New Stadium, an upper elementary STEM curriculum focused on concepts related to renewable and non-renewable resources. In this unit, students are contracted by a sports team to help design an environmentally friendly stadium (Lesson 1). Specifically, students are asked to use evidence-based reasoning to make design decisions regarding the location, building materials, and energy source for the stadium. Following a lesson on renewable and non-renewable resources, Lesson 3 calls for students to investigate and test the properties of three common building materials-concrete, wood, and steel. In Lesson 6, students research different alternative sources for generating electricity, and in Lesson 7, students compare the power output of the solar panel, windmill, and waterwheel prototypes to determine which renewable energy source(s) would supply the stadium with adequate power. In Lesson 7 , students create graphs, calculate averages, and analyze data to guide their energy source decisions. In Lesson 8, students use maps and weather data to determine the availability of different renewable energy sources, allowing them to choose a specific energy source for the stadium and to select a site for the stadium based on the availability of that energy source.

Table 4 STEM units by broad curricular type

\begin{tabular}{llll}
\hline & Physical science & Life science & Earth science \\
\hline Coherent science unit with a loosely connected EDC & 0 & 6 & 1 \\
Engineering design-focused unit with limited connections to science content & 0 & 0 & 9 \\
Engineering design unit with science content as context & 0 & 5 & 0 \\
Integrated and coherent STEM unit & 18 & 3 \\
\hline
\end{tabular}




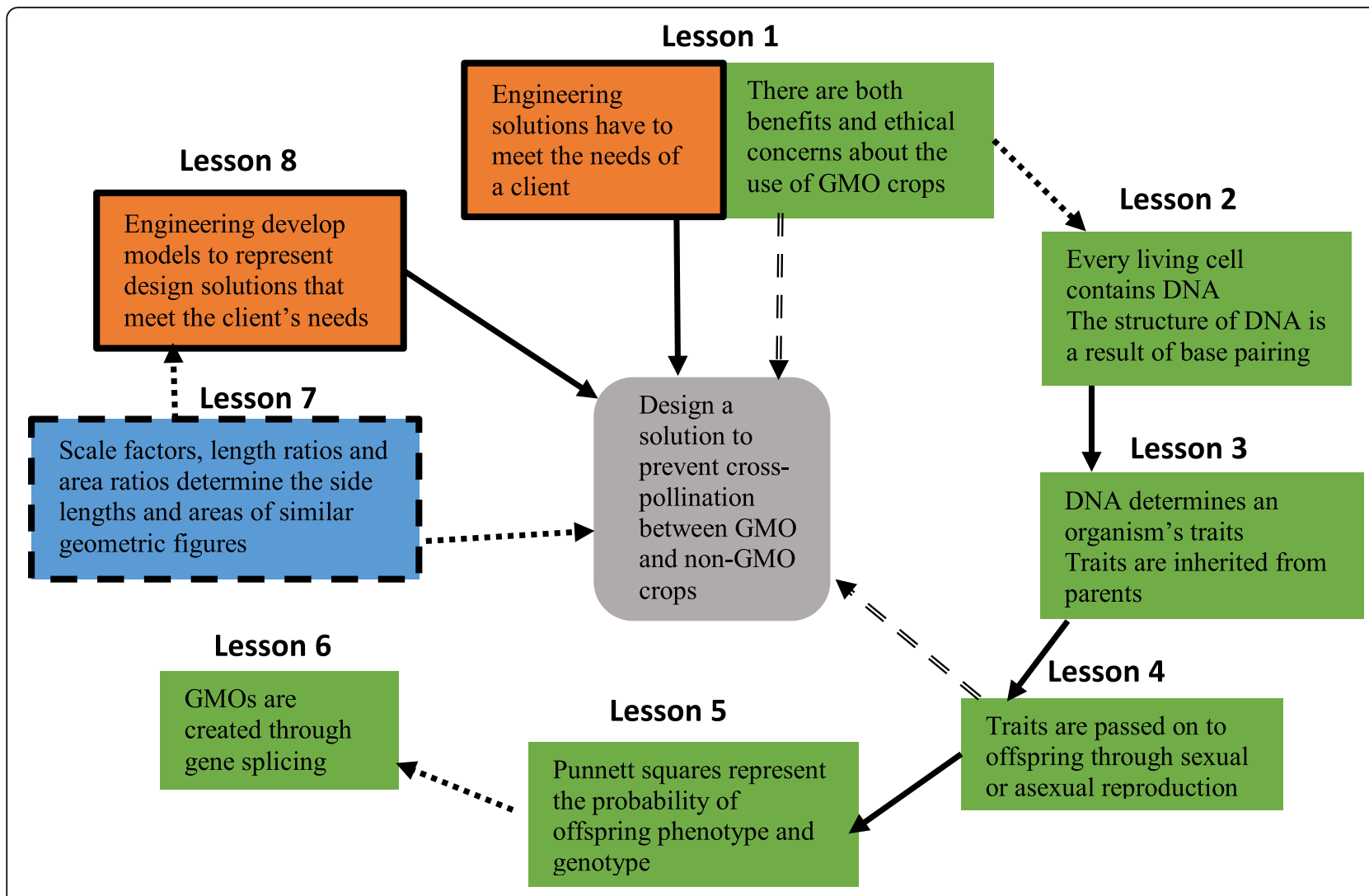

Science

Engineering

Mathematics

Fig. 2 Conceptual flow graphic for the GMO Corn curriculum

Finally, in Lesson 9, students complete a proposal to the client sharing their design and the rationale for their design choices.

The CFG for the New Stadium curriculum (Fig. 3) shows that the unit breaks down into two mini-units, first to select building materials, and second to select an energy source. In each mini-unit, the central storyline uses the EDP as the conceptual flow of practices students engage in, with science lessons disrupting that flow. For example, in Lesson 3, students test the properties of steel, wood, and concrete. Before making a decision about building materials, Lesson 4 is inserted wherein students learn about how to process natural resources (e.g., how iron is extracted from iron ore). While the processing of natural resources has an environmental impact, the decision between the three selected materials (wood, steel, and concrete) is a technical decision based solely on the properties of materials. With the exception of Lesson 8, the science lessons do not provide necessary content to propose design solutions. Typical of all CFGs in this category, the majority of the lessons are focused on engineering content, and the coherence of the storyline is developed through students engaging in a series of engineering lessons aligned with the EDP.

\section{Engineering design unit with science as context}

This curricular type also included STEM units that used the EDP as the structure or storyline for the unit. However, science-focused lessons were only used to provide contextual background to the ED. This curricular type is illustrated by the example unit Greenhouse, an upper elementary STEM unit intended to address life science standards related to plants and plant growth. In Lesson 1, students are introduced to the EDC through a client letter. The client is a vendor at a local Farmers' Market who wants to sell tomatoes earlier in the season. Lessons 2-5 follow the EDP, starting with the testing and selection of materials to build a greenhouse in Lesson 2. In Lesson 3, students create a plan for a greenhouse that meets the client's size and budget criteria, and in Lesson 4 , the students build and test a prototype of their proposed design by graphing the temperature of their prototype over a 10-min time-period in dark and light conditions. Lesson 5 is a science lesson where students 


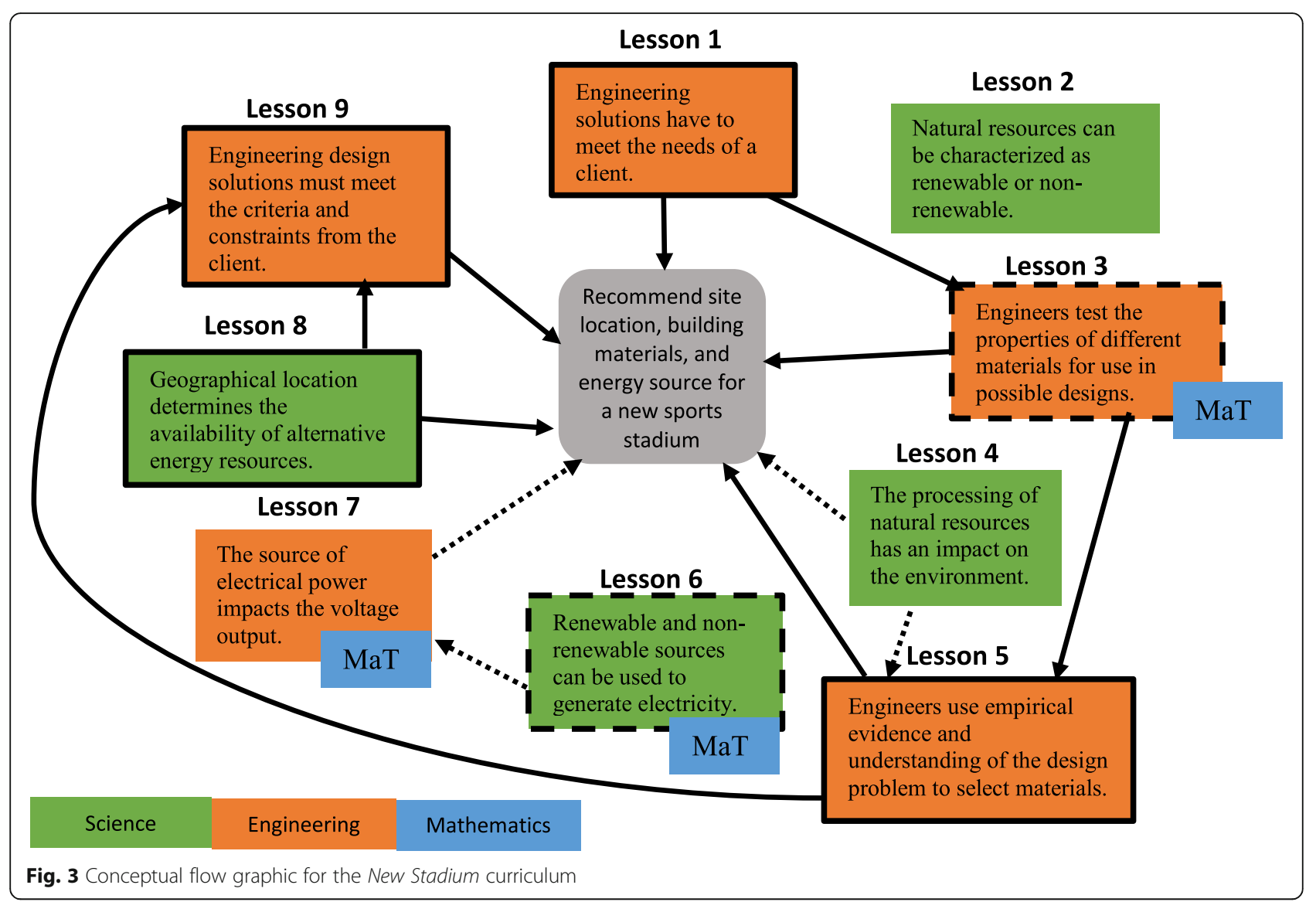

learn about the plant structures and functions and collect data about tomato seedling growth on an ongoing basis. In Lesson 6 , the students redesign their greenhouse prototype based on data and graphs generated in Lessons 4 and 5. Finally, in Lesson 7, students write a letter to the client, including their greenhouse designs and the evidence-based reasoning in support of their designs.

The CFG for the Greenhouse curriculum (Fig. 4) illustrates a unit where the coherence of the storyline is based on the EDP. However, unlike the units in the previous category (engineering design-focused unit with limited connections to science content); the science in these curricula is not even weakly conceptually linked to the EDC. In the Greenhouse unit, the science content related to plant structures is simply contextual; it is not necessary to be able to describe the function of different plant structures (e.g., stem, leaves, flowers) to design a greenhouse. In fact, the science relevant to building a greenhouse is related to heat transfer, which is not included in the unit. Instead, students are asked to make decisions about materials based solely on empirical data from testing the materials in Lesson 2 rather than applying conceptual knowledge about heat transfer to the problem. This disconnect between the science content within the lessons and the central EDC was characteristic of all CFGs in this category. However, sciencefocused lessons leveraged the context of the real-world problem as a rationale for learning science concepts. While it was not necessary to learn about the function of plant structures to propose solutions to the EDC, it was contextually relevant to grow seeds in the greenhouse prototypes, opening up the opportunity to teach about botany-related concepts.

\section{Integrated and coherent STEM curriculum}

This curricular type also included STEM units that used the EDP as the structure or storyline for the unit. However, all or almost all science-focused lessons of units in this category were conceptually linked to the EDC, providing important scientific knowledge and data needed to make decisions. This curricular type is illustrated by the example unit Improving the Mechanical Claw, an upper elementary curriculum unit focused on concepts related to electromagnets and magnetism. Lesson 1 introduces students to the EDC through a client letter from Arcade Games, who is contracting students to design a new electromagnet component to add to a crane arm (thus replacing the "claw") for their version of a mechanical claw game. According to Arcade 


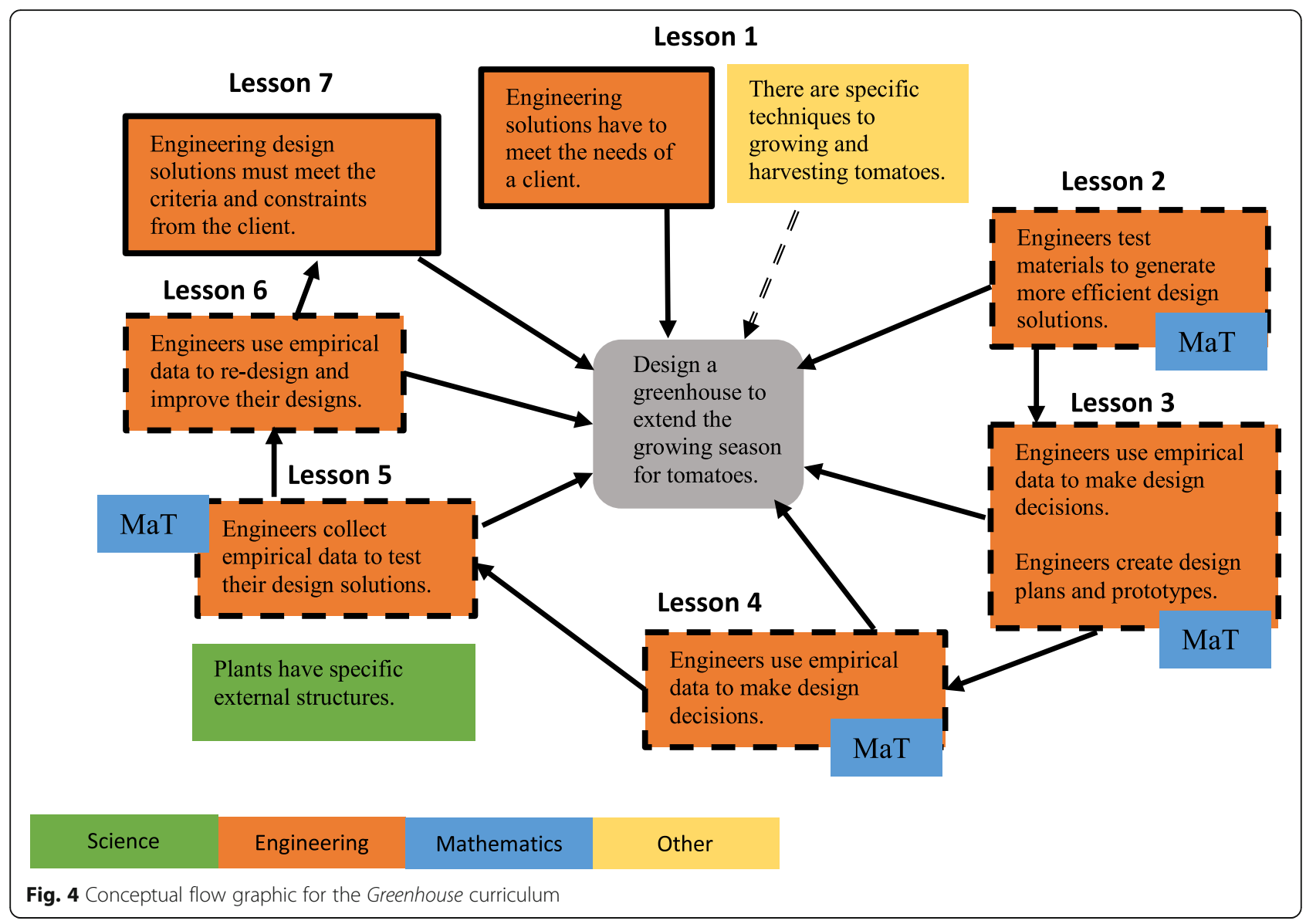

Games, claw games have recently been exposed as being rigged and unfair, so the company wants students to design and create a model of a new arm attachment for the game, using an electromagnet as opposed to a traditional mechanical claw. In Lessons 2-4, students explore the different variables that impact the strength of an electromagnet by collecting data on the number of washers that can be picked up under different conditions. In Lessons 3 and 4, students calculate the average of data across multiple trials and create graphs showing the impact of each variable on the average number of washers picked up. In Lesson 5, students apply their knowledge about electromagnets to develop and test an initial prototype for their electromagnetic arm. In Lesson 6 , students explore the magnetic properties of different materials. In Lesson 7, students redesign their electromagnetic arm to pick up a plastic toy with a metal tag; and in Lesson 8, students prepare a video presentation to explain their design to the client.

The CFG for the Improving the Mechanical Claw curriculum (Fig. 5) shows integration of the STEM disciplines across the unit, with science, mathematics, and engineering represented throughout the unit. The CFG also reveals a cohesive storyline throughout the unit (with the exception of Lesson 6). Each lesson develops important concepts necessary to design an electromagnet to add to the crane arm as requested by the client. For example, students were expected to use data on important variables for electromagnets (e.g., number of coils, gage of wire, number of batteries) from Lessons 3 and 4 to provide evidence for their design decisions. Each lesson included a new memo from the client to maintain the storyline and connect learning to the EDC. Thus, even in a lesson that was primarily focused on science and/or mathematics content, the context of the EDC was still maintained.

While CFGs in this category showed high levels of integration and conceptual coherence, the CFGs sometimes revealed issues in the STEM curriculum units. For example, in Improving the Mechanical Claw curriculum, Lesson 6 had weaker connections to the previous lesson and to the overarching unit goal. Lesson 6 was an investigation of the magnetic properties of different materials to address the contextual issue that plastic toys in the game need a metallic tag to work with an electromagnetic "claw." While magnetic properties are a relevant science standard, this content is not necessary for the design of the electromagnet. 


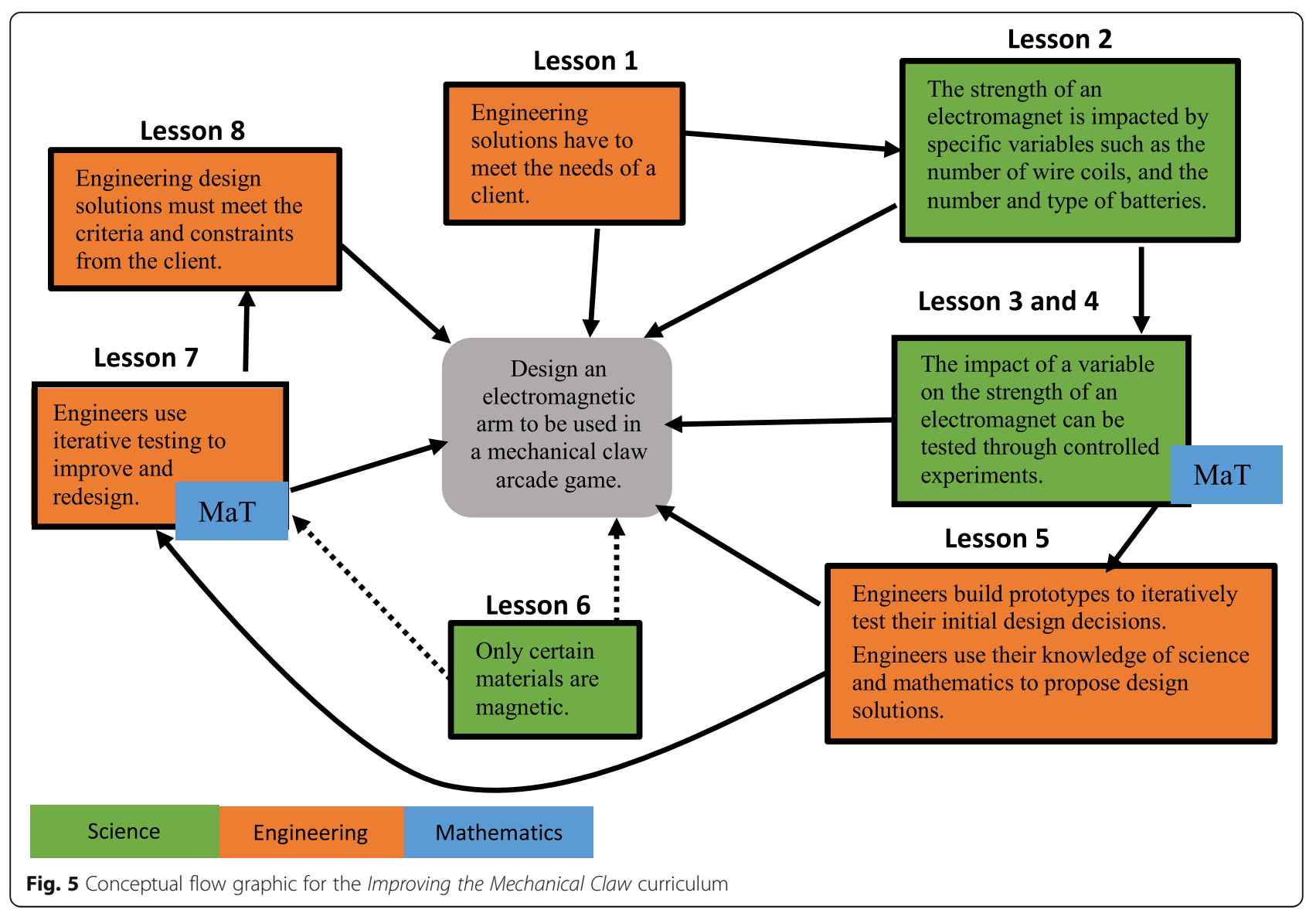

\section{Discussion}

Nature of coherence and integration within STEM units Analysis of the CFGs revealed two different types of integration between science (and occasionally mathematics) and engineering: conceptual and contextual. In this discussion, we also address how mathematics was integrated into these units.

\section{Conceptual integration}

Conceptual integration occurred frequently within the integrated curricular type, as the science and mathematics concepts learned throughout the curriculum were relevant and necessary to developing solutions to the EDC. The strong conceptual connections between science and mathematics concepts and the EDC, shown by arrows connecting science and mathematics-focused lessons to the central EDC, illustrates adherence to the indicator of application of SEM knowledge to the realworld problem or EDC from the Framework for Quality K-12 Engineering Education (Moore, Glancy, et al., 2014) and the Quality Integrated STEM Framework (Moore, Stohlmann, et al., 2014). However, conceptual connections between science (and mathematics) content and the EDC in the other curricular types were either absent or weakly present. In the science as context category, science content in the lessons was rarely conceptually connected to the EDC. In the coherent science unit and engineering design-focused curricular types, some science and mathematics content was necessary for making design decisions, but most science and mathematics concepts in the lessons were not necessary within the context of the EDC. This is problematic, as while all of the curricula engaged students in engineering practices to propose and iteratively test design solutions to an EDC, without conceptual connections between the science content and the EDC, students are potentially left to tinker rather than apply science knowledge to design decisions. Regardless of the level of conceptual integration, the integration of science and engineering is predominantly multidisciplinary in nature, with distinct science and engineering lessons; even when science lessons provide necessary content knowledge and data for use in the engineering lessons, they stand alone as lessons intended to teach science concepts. Indeed, many of the science lessons were taken from existing science units with minor modifications for use in the new integrated STEM curricula. A strength of this multidisciplinary approach, with lessons that have explicit learning outcomes for science content, is the promotion of conceptual learning of science. However, care needs to 
be taken that the science lessons are also explicitly linked to the EDC to maintain integration and a coherent curricular storyline.

\section{Contextual integration}

Contextual integration occurred in two different ways across the STEM curricula analyzed in this study: (i) the use of a client to contextualize the learning of science and mathematics content and (ii) the use of science content to better understand the EDC and provide more detailed contextualization of the problem.

Use of a client to contextualize learning In all cases, an EDC was used as a motivating and engaging context (Moore, Stohlmann, et al., 2014) in the first lesson of the unit with the stated goal of providing a context for learning science and mathematics content within the STEM unit. A client letter, which introduced the problem and provided specifics about the relevant criteria and constraints, was used to introduce the EDC. In the integrated curricular type, this contextualization of the learning through the client occurred throughout the unit, with the client providing the motivation or need to learn the science and mathematics content. These curricula used memos from the client or guided the teacher to remind the students about the client and why the science or mathematics they learned in a given lesson was relevant to the EDC. The engineering design-focused units each included lessons, in addition to the opening lesson, that used the client to contextualize learning. In lessons where contextual integration through the client was identified between the science or mathematics content and the EDC, conceptual integration was also included. In contrast, science lessons not conceptually integrated with the EDC were never contextually integrated with a client memo and only rarely contextualized through suggestions in the teacher guidelines to the teacher to remind the students about the EDC and the needs of the client. In other words, contextual integration through the use of a client was difficult in the absence of conceptual integration, when the science and mathematics concepts were not necessary to develop design solutions. This reflects a disconnect between the EDC and the learning of science and mathematics concepts that cannot be remedied through the use of a client to provide a storyline for the curriculum as students work through the EDP.

In the case of the coherent science unit curricular type, the EDC simply formed bookends around an existing science curriculum. The EDC was rarely mentioned in the science lessons after the first lesson of the unit and was only reintroduced as the culminating activity of the unit, which did not leverage the science concepts learned in previous lessons. While an EDC and the client were introduced in Lesson 1, this did not ultimately provide contextualization for learning science and mathematics content in a consistent and coherent manner throughout the unit.

Use of science content to contextualize the EDC Science content was sometimes used to contextualize the EDC and motivate learning even if the content was not directly necessary for developing design solutions. For example, in the Science as Context curricular type, science lessons were often included to provide motivational and contextual details to the EDC. In the Greenhouse curriculum, students learned about the growing season in their location and agricultural practices for tomato production (see Fig. 4). This information is not relevant to making design decisions about the construction of a greenhouse prototype, but it does add contextual richness to the problem, as well as opportunities to learn science concepts. Similarly, in the Save the Moose curriculum, students learned about the impact of climate change on moose and their environment as part of the lesson sequence introducing the EDC. While this learning was not conceptually linked to the EDC, which called for the design of a process and product for application of tick preventative to the moose, it provided important contextual integration between grade-level science standards and the real-world problem. Similarly, in the coherent science and engineering design-focused curricular types, science content was explicitly taught and sometimes used to provide contextual information about the EDC. For example, in GMO Corn, students read about GMOs and engaged in a discussion about the pros and cons of growing GMO food to provide deeper contextual relevance to the real-world problem (see Fig. 2).

\section{Integration of mathematics}

Unlike science concepts that were present with explicit learning outcomes, mathematics concepts represented less than $10 \%$ of the main concepts to be learned in each lesson across all four CFG categories. However, mathematics was found in all of the analyzed curricula as a tool for data analysis, and students were frequently asked to keep track of budgets for their design solutions, construct graphs of science and/or engineering data, calculate averages of multiple trials, create scaled models, and perform calculations such as area, volume, and density. Mathematics integration was most commonly in the form of mathematics as a tool to analyze data in the service of science or engineering. Mathematics educators debate what should be considered mathematics, as the types of mathematics commonly used in the real-world, such as statistics, data science, and applied mathematics, are more appropriately labeled mathematical sciences (Quinn, 2012) rather than pure mathematics (Moore \& 
Cobb, 2000). However, the goal of this study is not to debate what counts as mathematics in $\mathrm{K}-12$ classrooms, but to explore the ways in which mathematics is currently incorporated into integrated STEM curricula. Similar to Reynante et al. (2020), who indicates there is often a "blurring [of] the boundary of where mathematics ends and science begins" (p. 4) in K-12 classrooms, this blurring of the disciplines was evident in the nature of the integration of mathematics in these integrated STEM curricula. In other words, the integration of mathematics was primarily interdisciplinary in nature, as the boundaries between mathematics and science (or engineering) started to break down because mathematics was included as applied mathematics rather than pure mathematics. As such, the CFGs can be deceptive about the degree of integration of mathematics if mathematics is only included when being taught as a main concept. As noted by Kelley and Knowles (2016), STEM practices are a strong thread within a curricular unit supporting integration, and this was certainly the case with mathematics.

Unfortunately, this implicit integration of mathematics as a tool, which has been prevalent for decades in science and now STEM classrooms (e.g., Berlin \& White, 1995; Davison et al., 1995; Huntley, 1998; Walker, 2017; Zhang, Orrill, \& Campbell, 2015), leads to only small impacts on students' mathematical knowledge (e.g., Becker \& Park, 2011; Honey et al., 2014). While it is difficult to imagine engaging in science or engineering without using mathematical practices, these mathematical connections are often implicit and not always transparent to students. Successful mathematics integration requires that mathematics concepts are foregrounded with explicit learning outcomes (Silk, Higashi, Shoop, \& Schunn, 2010). Hurley (2001) reported the greatest effect sizes for mathematics learning when students learned science and mathematics in sequence using a multidisciplinary approach as opposed to an interdisciplinary approach. In other words, a multidisciplinary approach to integration should not be viewed as lesser than interdisciplinary and transdisciplinary approaches to integrated STEM as suggested by some researchers (e.g., Vasquez et al., 2013). Conceptual learning of mathematics (and science) is improved through a multidisciplinary approach that allows each discipline to be purposefully foregrounded within a unit with explicit student learning outcomes, rather than being backgrounded as a tool (Baldinger et al., 2021; Hurley, 2001). Like other researchers (e.g., Li \& Schoenfeld, 2019), we argue for the need for further research about the nature of the $\mathrm{M}$ in STEM.

\section{Curricular coherence}

Curricular coherence was present to some degree in all CFG curricula types. In the integrated, engineering design-focused, and science as context units, the EDP provided the storyline, with students defining the problem, designing and implementing solutions through an iterative testing and improvement cycle, and deciding on a final solution that met the needs of the client. In integrated and engineering design-focused units, the context of the client and the EDC provided a story arc to contextualize science lessons as providing the knowledge needed to develop designs for the client. In units with strong contextual coherence, the students were in continual communication with the client. For example, students received memos from the client asking for information, provided preliminary designs for the client to review, and had opportunities to ask questions of the client to clarify their needs. Teachers were also directed to remind the students about the client and the criteria and constraints of the EDC at the start of lessons.

Disciplinary conceptual coherence was present between the science lessons for units within the coherent science curricular type. However, as described previously, there was no conceptual integration between science and engineering in this category. Within the engineering design-focused units, the problems with conceptual integration created a break in the coherence of the curricular storyline. The addition of science lessons for the purpose of addressing grade-level standards that were not necessary to either contextualize the EDC or to create solutions for the client were disruptive to the coherence of the storyline provided by the EDC and the client.

A summary of the findings related to that nature of integration (conceptual and contextual) and curricular coherence is provided in Table 5. While curricular coherence is present to some degree in all CFG categories, curricular coherence through the entire unit can only happen when both conceptual and contextual integration are strong, as in the case of the integrated curricular type.

\section{Differences in coherence and integration among the science disciplines}

Curricular coherence and strong integration were present for all of the physical science STEM curricula, but only three Earth science and no life science STEM curricula. Conceptual integration through the use of an EDC appears to be more challenging in life and Earth sciences at the K-12 level; previous work has noted that physical sciences are typically well suited for integration with engineering (Dare et al., 2014). While fields such as genetic and biomedical engineering are applied spaces where biological concepts are applied to solving realworld problems, the level of the biology content is often at a higher level than appropriate in K-12 classrooms. Indeed, the number of NGSS performance expectations designated as explicitly integrating traditional science content with engineering through either the engineering 
Table 5 Summary of nature of integration and curricular coherence by CFG category

\begin{tabular}{|c|c|c|c|}
\hline & Conceptual integration & Contextual integration & Curricular coherence \\
\hline $\begin{array}{l}\text { Coherent science unit with } \\
\text { loosely connected EDC }\end{array}$ & $\begin{array}{l}\text { Science and mathematics } \\
\text { concepts are rarely needed } \\
\text { for design decisions }\end{array}$ & $\begin{array}{l}\text { - Bookended the unit - introduced in } \\
\text { the first lesson and returned for a } \\
\text { culminating activity. } \\
\text { - Science content sometimes used to } \\
\text { provide context about EDC. }\end{array}$ & $\begin{array}{l}\text { - Disciplinary coherence across science lessons. } \\
\text { - Disconnect between science and engineering } \\
\text { lessons. }\end{array}$ \\
\hline $\begin{array}{l}\text { Engineering design-focused } \\
\text { unit with limited } \\
\text { connections to science } \\
\text { content }\end{array}$ & $\begin{array}{l}\text { Science and mathematics } \\
\text { concepts sometimes needed } \\
\text { for design decisions. }\end{array}$ & $\begin{array}{l}\text { - Always present when conceptual } \\
\text { integration is present. } \\
\text { - Weakly present through verbal } \\
\text { reminders about the client's needs } \\
\text { when conceptual integration is } \\
\text { lacking. } \\
\text { - Science content sometimes used to } \\
\text { provide context about EDC. }\end{array}$ & $\begin{array}{l}\text { - Overall coherence provided by EDC storyline } \\
\text { (through client) and EDP. } \\
\text { - Science lessons are often disruptive to } \\
\text { curricular coherence }\end{array}$ \\
\hline $\begin{array}{l}\text { Engineering design unit with } \\
\text { science content as context }\end{array}$ & $\begin{array}{l}\text { Science concepts are never } \\
\text { needed for design decisions }\end{array}$ & $\begin{array}{l}\text { Science provided context for } \\
\text { understanding the real-world } \\
\text { problem addressed by the EDC. }\end{array}$ & $\begin{array}{l}\text { - Overall coherence provided by EDC storyline } \\
\text { (through client) and EDP. } \\
\text { - Science lessons are often disruptive to } \\
\text { curricular coherence }\end{array}$ \\
\hline $\begin{array}{l}\text { Integrated and coherent } \\
\text { STEM unit }\end{array}$ & $\begin{array}{l}\text { - Frequent, strong connections } \\
\text { between science and } \\
\text { mathematics concepts and } \\
\text { the EDC. } \\
\text { - Science and mathematics } \\
\text { concepts are necessary for } \\
\text { making design decisions. }\end{array}$ & $\begin{array}{l}\text { Occurred throughout the unit with } \\
\text { explicit connections to the client } \\
\text { and the EDC to motivate learning of } \\
\text { science and mathematics concepts }\end{array}$ & $\begin{array}{l}\text { - Overall coherence provided by EDC storyline } \\
\text { (through client) and EDP. } \\
\text { - Science lessons are occasionally disruptive to } \\
\text { curricular coherence }\end{array}$ \\
\hline
\end{tabular}

practice or disciplinary core ideas in the Earth and life sciences are lower than in the physical sciences. Table 6 provides details about these performance expectations for upper elementary and middle school.

Performance expectations in the physical sciences explicitly call for the application of science concepts such as heat transfer, electricity, Newton's laws, and magnetism, to developing engineering design solutions. Our CFG analysis showed that integrated STEM curricula addressing physical science concepts had strong conceptual integration. Conversely, performance expectations in the Earth and life sciences more often call for the evaluation of design solutions rather than engaging students in the full EDP. In the cases where the EDP is invoked, the examples require the application of physical science concepts rather than Earth or life science concepts. This is also evident in the CFG analysis, for example, the Greenhouse curriculum uses physical science concepts of heat transfer to create successful design solutions, not life science concepts. Earth and life science topics can provide relevant and interesting contexts for engaging students in the EDP; however, the nature of integration between science concepts and the EDC is often weak. As noted by previous researchers (e.g., Bryan, Moore, Johnson, \& Roehrig, 2016), the Earth and life sciences may provide opportunities to integrate other aspects of engineering than the EDP, such as ethics, and to provide context to engineering lessons (e.g., Crotty et al., 2017).

\section{Conclusion}

Researchers agree that a real-world problem is a critical component of integrated STEM teaching (Kelley \&
Knowles, 2016; Moore, Stohlmann, et al., 2014; Sanders, 2009). In this study, the real-world problem was presented as an EDC. The use of an EDC can provide contextual integration by using the client as a motivating storyline for students to engage in learning science and mathematics content. When explicit connections to the client are included throughout the curriculum, the client provides a consistent storyline and contextual coherence. In addition, the use of an EDC engages students in the EDP, and the arc of the storyline is developed as students engage in the EDP. Reynante et al. (2020) argue that "disciplinary practices may provide a useful framework for integrating the various STEM subjects" (p. 3). Our study shows that engineering practices can serve as a contextual integrator within a STEM unit. Integration through engineering practices also enhances the notion of STEM as engaging students in addressing real-world problems through the authentic practices of STEM professionals (Kelley \& Knowles, 2016; Reynante et al., 2020). As such, context is provided through an authentic problem or EDC, as well as by engaging in authentic STEM practices that are important to developing conceptual understanding of STEM (Kelley \& Knowles, 2016; Lee, Quinn, \& Valdes, 2013) and addressing standards related to engineering design (e.g., NGSS Lead States, 2013).

The utilization of an EDC also provides the potential for conceptual integration because of the inherent interdisciplinary nature of engineering. Engineering is a discipline in which knowledge of the mathematical and natural sciences gained by study, experience, and practice is 
Table 6 Integration of engineering practices within the NGSS performance expectations

\begin{abstract}
Earth sciences
MS Apply scientific principles to design a method for monitoring and minimizing a human impact on the environment. Examples of human impacts can include water usage (such as the withdrawal of water from streams and aquifers or the construction of dams and levees), land usage (such as urban development, agriculture, or the removal of wetlands), and pollution (such as of the air, water, or land).

Elem Generate and compare multiple solutions to reduce the impacts of natural Earth processes on humans. Examples of solutions could include designing an earthquake-resistant building and improving monitoring of volcanic activity.

Make a claim about the merit of a design solution that reduces the impacts of a weather-related hazard. Examples of design solutions to weather-related hazards could include barriers to prevent flooding, wind resistant roofs, and lighting rods.
\end{abstract}

Life sciences

MS Evaluate competing design solutions for maintaining biodiversity and ecosystem services. Examples of ecosystem services could include water purification, nutrient recycling, and prevention of soil erosion.

Elem Make a claim about the merit of a solution to a problem caused when the environment changes and the types of plants and animals that live there may change. Examples of environmental changes could include changes in land characteristics, water distribution, temperature, food, and other organisms.

Physical sciences

MS Undertake a design project to construct, test, and modify a device that either releases or absorbs thermal energy by chemical processes.

Apply Newton's Third Law to design a solution to a problem involving the motion of two colliding objects. Examples of practical problems could include the impact of collisions between two cars, between a car and stationary objects, and between a meteor and a space vehicle.

Apply scientific principles to design, construct, and test a device that either minimizes or maximizes thermal energy transfer. Examples of devices could include an insulated box, a solar cooker, and a styrofoam cup.

Elem Apply scientific ideas to design, test, and refine a device that converts energy from one form to another. Examples of devices could include electric circuits that convert electrical energy into motion energy of a vehicle, light, or sound; and, a passive solar heater that converts light into heat.

Define a simple design problem that can be solved by applying scientific ideas about magnets. Examples of problems could include constructing a latch to keep a door shut and creating a device to keep two moving objects from touching each other.

applied with judgment to develop ways to utilize, economically, the materials and forces of nature for the benefit of mankind (Accreditation Board for Engineering and Technology, 2001).

Application of science and mathematics knowledge is both central to the discipline of engineering and a critical component of integrated STEM (e.g., Moore, Glancy, et al., 2014; Moore, Stohlmann, et al., 2014). Integrated STEM curricula that purposefully include science and mathematics concepts necessary to develop solutions to the EDC engage students in authentic engineering experiences and provide conceptual integration between science, mathematics, and engineering (e.g., Moore, Glancy, et al., 2014; Moore, Stohlmann, et al., 2014). However, the alignment of grade-level science and mathematics standards with the necessary science and mathematics content for the EDC can be problematic. Teachers and curriculum developers need to take care that planning for integrated STEM starts with science and mathematics standards and include lessons that explicitly teach and develop a conceptual understanding of these concepts. Policymakers and STEM education researchers do not argue that every unit should use an integrated STEM approach to learning. In fact, engineering educators call for the inclusion of components of quality engineering throughout K-12 education when the inclusion of engineering can enhance content learning (Moore, Glancy, et al., 2014). The findings from this study provide some preliminary guidance on science topics that lend themselves to conceptual or contextual integration. Further research is needed to determine the efficacy of integrated STEM approaches in specific science content areas.

Previous research has argued that it is important for students to understand the connections between the STEM disciplines while cautioning that the relationships among the disciplines are complex (English, 2016; Honey et al., 2014; Moore, Glancy, et al., 2014). Integrated STEM curricula must provide explicit details about how the disciplines are integrated and support in the application of disciplinary knowledge in integrated contexts (Reynante et al., 2020). When a science or mathematics concept from a lesson is relevant to the EDC, it is important that these connections are made explicit to the students, either through a client memo or other connection made by the teacher between the content to be learned and the EDC.

Finally, the CFG analysis shows a tension between curricular coherence and incorporating all relevant gradelevel science standards when using an integrated STEM approach. Even in the case of curricula in the integrated category, not all of the science lessons were conceptually linked to the EDC. For example, in the Museum Security curriculum (see Fig. 1), the content of Lesson 2 (understanding the wave nature of light) is not necessary to 
develop possible design solutions. Indeed, only two science topics (heat transfer and electromagnetism) generated integrated STEM curricula that included all relevant standards for the topic and connected these concepts to the EDC. The results of this study indicate the difficulties faced by teachers developing integrated STEM curricula in balancing coherence of the required science content standards and coherence to the EDC. However, the goal of this study was to understand the range of integration within STEM curricula, not to determine which model is better for student learning. Further research is needed to understand the impact of different forms of integration on student outcomes.

\section{Implications}

The development of new integrated STEM curricula for K12 classroom use is necessary to address global STEM initiatives and policies. Curricular analysis is a key first step in either developing or selecting integrated STEM curricula, and the CFG process provides an effective visual representation at the curricular level that can be used by teachers, researchers, and teacher educators. Specifically, CFGs provide a process to explore integration and curricular coherence in integrated STEM curricula. Existing STEM curriculum evaluation rubrics, such as the STEM-ICA (Guzey et al., 2016); do not provide any detail about the nature of integration and curricular coherence beyond a single score on two items. However, the visual nature of the CFGs allows for a quick analysis of overall integration and coherence of the curriculum and can serve as a diagnostic tool to make curricular modifications to improve a STEM curriculum. For example, the CFG of the Improving the Mechanical Claw curriculum (see Fig. 5) shows that Lesson 6 is problematic in terms of conceptual coherence. If the concepts from Lesson 6 were moved to a new Lesson 2 , a more basic concept about magnetism would be introduced earlier in the unit and provide a conceptual link to understanding the design of the electromagnet in terms of the materials used in the core of the electromagnet.

It is critical to note that the CFG provides information about only two important aspects of integrated STEM curricula: integration and curricular coherence. Frameworks for integrated STEM education also call for the inclusion of other critical components, such as the use of studentcentered pedagogies and opportunities for students to engage in twenty-first century skills, particularly teamwork and collaboration. A thorough analysis of the quality of an integrated STEM curriculum would need to use an instrument such as the STEM-ICA (Guzey et al., 2016; Walker et al., 2018) in conjunction with the CFG, as neither process alone provides a full analysis. The work presented here may assist others in determining the viability of new curricula by addressing key concerns related to conceptual and contextual coherence within integrated STEM curricula to lead to greater student learning and success.

\section{Abbreviations}

CFG: Conceptual flow graphic; EDC: Engineering design challenge; EDP: Engineering design process; NGSS: Next Generation Science Standards; NRC: National Research Council; PD: Professional development;

STEM: Science, Technology, Engineering, and Mathematics

\section{Acknowledgements}

This research was made possible by the National Science Foundation grant \#DRL-1238140. The findings, conclusions, and opinions herein represent the views of the authors and do not necessarily represent the view of personnel affiliated with the National Science Foundation.

\section{Authors' contributions}

The first author analyzed all of the data and created the CFGs. The second, third, and fourth authors reviewed the findings and provided expert guidance through each revision. All authors read and approved the final manuscript.

\section{Funding}

This material is based upon work supported by the National Science Foundation grant 1238140. Opinions, findings, and conclusions or recommendations expressed in this material are those of the authors and do not necessarily reflect the views of the National Science Foundation.

\section{Availability of data and materials}

The thirteen published integrated STEM curricula are available upon request.

\section{Competing interests}

The authors declare that they have no competing interests

\section{Author details}

${ }^{1}$ STEM Education Center, University of Minnesota, Learning and Environmental Sciences 320, 1954 Buford Ave, St. Paul, MN 55108, USA. ${ }^{2}$ Department of Teaching and Learning, Florida International University, 11200 SW 8th Street, Miami, FL 33199, USA. ${ }^{3}$ Department of Education, St. Catherine University, 2004 Randolph Ave. \#4040, St. Paul, MN 55105, USA. ${ }^{4}$ Caruth Institute for Engineering Education, Lyle School of Engineering, Southern Methodist University, PO Box 750278, Dallas, TX 75275, USA.

Received: 30 June 2020 Accepted: 7 December 2020

Published online: 13 January 2021

\section{References}

Accreditation Board for Engineering and Technology (2001). Criteria for accrediting engineering programs, Engineering Accreditation Commission of the Accreditation Board of Engineering and Technology. Available on-line at http:// www.abet.org/criteria.html.

Accreditation Board for Engineering and Technology (2019). Criteria for accrediting engineering programs. Retrieved from https://www.abet.org/ accreditation/accreditation-criteria/accreditation-policy-and-proceduremanual-appm-2019-2020/

Baldinger, E. E., Staats, S., Covington-Clarkson, L. M., Gullickson, E., Norman, F., \& Akoto, B. (2021). Returning voice to the silent M: A review of conceptions of mathematics in integrated STEM Education. In J. Anderson, \& Y. Li (Eds.), Integrated Approaches to STEM Education: An International Perspective.

Beane, J. (1995). Curriculum integration and the disciplines of knowledge. The Phi Delta Kappan, 76, 616-622.

Becker, K., \& Park, K. (2011). Effects of integrative approaches among science, technology, engineering, and mathematics (STEM) subjects on students' learning: A preliminary meta-analysis. Journal of STEM Education, 12(5), 23-38.

Berlin, D. F., \& White, A. L. (1995). Connecting school science and mathematics. In P. A. House, \& A. F. Coxford (Eds.), Connecting mathematics across the curriculum. 1995 National Council of Teachers of Mathematics Yearbook, (pp. 22-33). Reston: National Council of Teachers of Mathematics.

Bintz, J. (2009). How to select program for you inquiry classrooms in The Biology Teachers Handbook, (4th ed., ). Arlington: National Science Teachers Association.

Brooks, G. J., \& Brooks, G. M. (1993). In search of understanding: The case for constructivism classroom. Alexandria: Association for Supervision and Curriculum Development. 
Brophy, S., Klein, S., Portsmore, M., \& Rogers, C. (2008). Advancing engineering education in P-12 classrooms. Journal of Engineering Education, 97(3), 369-387.

Bryan, L. A., Moore, T. J., Johnson, C. C., \& Roehrig, G. H. (2016). Integrated STEM education. In C. C. Johnson, E. E. Peters-Burton, \& T. J. Moore (Eds.), STEM Road Map: STEM Road Map: A framework for integrated STEM education. New York: Routledge.

Bybee, R. W. (2010). Advancing STEM education: a 2020 vision. Technology and Engineering Teacher, 70(1), 30-35.

Bybee, R. W. (2013). A case for STEM education. Arlington: National Science Teachers' Association Press.

Chi, M. T. H., Glaser, R., \& Rees, E. (1982). Expertise in problem solving, (vol. 1). Hillsdale: Lawrence Erlbaum Associates.

Cira, N. J., Chung, A. M., Denisin, A. K., Rensi, S., Sanchez, G. N., Quake, S. R., \& Riedel-Kruse, I. H. (2015). A biotic game design project for integrated life science and engineering education. PLoS Biology, 13(3). https://doi.org/10. 1371/journal.pbio.1002110.

Cohen, L., Manion, L., \& Morrison, K. (2011). Research methods in education. New York: Routledge.

Corbin, J., \& Strauss, A. (2015). Basics of qualitative research, (4th ed., ). Thousand Oaks: Sage.

Crotty, E. A., Guzey, S. S., Roehrig, G. H., Glancy, A. W., Ring-Whalen, E. A., \& Moore, T. J. (2017). Approaches to integrating engineering in STEM units and student achievement gains. Journal of Pre-College Engineering Education Research (J-PEER), 7(2), 1-14

Cunningham, C. M., \& Carlsen, W. S. (2014). Teaching engineering practices. Journal of Science Teacher Education, 25, 197-210.

Czerniak, C. M., Weber, W. B., Sandmann, J. A., \& Ahern, J. (1999). Literature review of science and mathematics integration. School Science and Mathematics, 99(8), 421-430

Dare, E. A., Ellis, J. A., \& Roehrig, G. H. (2014). Driven by beliefs: understanding challenges physical science teachers face when integrating engineering and physics. Journal of Pre-College Engineering Education Research, 4(2), 1-13.

Davison, D. M., Miller, K. W., \& Metheny, D. L. (1995). What does integration of science and mathematics really mean? School Science and Mathematics, 95(5), 226-230.

DeBoer, G. E. (2014). The history of science curriculum reform in the United States. In N. Lederman, \& S. Abell (Eds.), Handbook of Research on Science Education, (vol. 2, pp. 759-578). New York and London: Routledge.

Douglas, J., Iversen, E., \& Kalyandurg, C. (2004). Engineering in the K-12 classroom: An analysis of current practices \& guidelines for the future. Washington, DC: American Society for Engineering Education.

Drake, S. M. (1991). How our team dissolved the boundaries. Educational Leadership, 49(2), 20-22

Drake, S. M. (1998). Creating integrated curriculum: Proven ways to increase student learning. Thousand Oaks: Corwin.

Dym, C. (1999). Learning engineering: Design, languages, and experiences. Journal of Engineering Education, 88(2), 145-148.

English, L. D. (2016). STEM education K-12: Perspectives on integration. International Journal of STEM Education, 3, 3. https://doi.org/10.1186/s40594 016-0036-1.

Fogarty, R. (1991). Ten ways to integrate the curriculum. Educational Leadership, 49(2), 61-65.

Guzey, S. S., Harwell, M., Moreno, M., Peralta, Y., \& Moore, T. J. (2017). The impact of design-based STEM integration curricula on student achievement in engineering, science, and mathematics. Journal of Science Education and Technology, 26, 207-222

Guzey, S. S., Moore, T. J., \& Harwell, M. (2016). Building Up STEM: An analysis of teacher-developed engineering design-based STEM integration curricular materials. Journal of Pre-College Engineering Education Research (J-PEER), 6(1), Article 2. https://doi.org/10.7771/2157-9288.1129.

Guzey, S. S., Ring-Whalen, E. A., Harwell, M., \& Peralta, Y. (2019). Life STEM: A case study of life science learning through engineering design. International Journal of Science and Mathematics Education, 17, 23-42.

Han, S., Capraro, R., \& Capraro, M. M. (2015). How science, technology, engineering, and mathematics (stem) project-based learning (pbl) affects high, middle, and low achievers differently: The impact of student factors on achievement. International Journal of Science and Mathematics Education, 13(5), 1089-1113.

Harwell, M., Moreno, M., Phillips, A., Guzey, S. S., Moore, T. J., \& Roehrig, G. H. (2015). A study of STEM assessments in engineering, science, and mathematics for elementary and middle school students. School Science and Mathematics, 115(2), 66-74.

Hirst, P. H. (1974). Knowledge and the curriculum: A collection of philosophical papers. London: Routledge and Kegan Paul.

Hmelo, C., Douglas, H., \& Kolodner, J. (2000). Designing to learn complex systems. Journal of the Learning Sciences, 9, 247-298.

Hoachlander, G., \& Yanofsky, D. (2011). Making STEM real: By infusing core academics with rigorous real-world work, linked learning pathways prepare students for both college and career. Educational Leadership, 68(3), 60-65.

Honey, M., Pearson, G., \& Schweingruber, A. (2014). STEM integration in K-12 education: Status, prospects, and an agenda for research. Washington: National Academies Press.

Huntley, M. A. (1998). Design and implementation of a framework for defining integrated mathematics and science education. School Science and Mathematics, 98(6), 320-327.

Hurley, M. M. (2001). Reviewing Integrated science and mathematics: The search for evidence and definitions from new perspectives. School Science and Mathematics, 101(5), 259-268.

Jacobs, H. H. (1989). Interdisciplinary curriculum: Design and implementation. Alexandria: Association for Supervision and Curriculum Development.

Kelley, T. R., \& Knowles, J. G. (2016). A conceptual framework for integrated STEM education. International Journal of STEM Education, 3(1), 1-11. https://doi.org/ 10.1186/s40594-016-0046-Z.

Lederman, N. G., \& Niess, M. L. (1997). Integrated, interdisciplinary, or thematic instruction? Is this a question or is it questionable semantics? School Science and Mathematics, 97(2), 57-58.

Lee, O., Quinn, H., \& Valdes, G. (2013). Science and language for English language learners in relation to Next Generation Science Standards and with implications for Common Core State Standards for English Language Arts and Mathematics. Educational Researcher, 42(4), 223-233.

Li, Y., \& Schoenfeld, A. H. (2019). Problematizing teaching and learning mathematics as "given" in STEM education. International Journal of STEM Education, 6(44). https://doi.org/10.1186/s40594-019-0197-9.

McFadden, J., \& Roehrig, G. H. (2020). Missed expectations: Teacher and coach tensions at the boundary of STEM integration in an elementary classroom. Disciplinary and Interdisciplinary Science Education Research, 2(4). https://doi. org/10.1186/s43031-020-00021-8.

Mehalik, M. M., Doppelt, Y., \& Schunn, C. D. (2008). Middle-school science through design-based learning versus scripted inquiry: Better overall science concept learning and equity gap reduction. Journal of Engineering Education, 97, 71-85.

Mintzes, J., Wandersee, J., \& Novak, J. (2000). Assessing science understanding: A human constructivist view. Orlando: Academic Press.

Monk, M., \& Osborne, J. (2000). Good practice in science teaching: What research has to say. Buckingham: Open University Press.

Moore, D. S., \& Cobb, G. W. (2000). Statistics and mathematics: Tension and cooperation. The American Mathematical Monthly, 107(7), 615-630.

Moore, T. J., Glancy, A. W., Tank, K. M., Kersten, J. A., \& Smith, K. A. (2014). A framework for quality K-12 engineering education: Research and development. Journal of Pre-college Engineering Education Research, $4(1), 1-13$.

Moore, T. J., \& Smith, K. A. (2014). Advancing the state of the art of STEM integration. Journal of STEM Education, 15(1), 5-10.

Moore, T. J., Stohlmann, M. S., Wang, H.-H., Tank, K. M., \& Roehrig, G. H. (2014). Implementation and integration of engineering in K-12 STEM education. In J. Strobel, S. Purzer, \& M. Cardella (Eds.), Engineering in pre-college settings: Research into practice. Rotterdam: Sense Publishers.

Moore, T. J., Tank, K. M., Glancy, A. M., \& Kersten, J. A. (2015). NGSS and the landscape of engineering in K-12 state science standards. Journal of Research in Science Teaching, 52(3), 296-318.

National Academy of Engineering. (2010). Standards for K-12 engineering education? Washington, DC: The National Academies Press.

National Academy of Engineering and National Research Council (2009). Engineering in K-12 education: Understanding the status and improving the prospects. Washington, DC: The National Academies Press.

National Academy of Science, National Academy of Engineering, and Institute of Medicine (2007). Rising above the gathering storm: Energizing and employing America for a brighter economic future. Washington D.C.: The National Academies Press.

National Research Council (1996). National Science Education Standards. Washington, DC: The National Academies Press. 
National Research Council (2009). Engineering in K-12 education: Understanding the status and improving the prospects. Washington, DC: The National Academies Press.

National Research Council (2011). Successful K-12 STEM education: Identifying effective approaches in science, technology, engineering, and mathematics. Washington, DC: National Academies Press.

National Research Council (2012). A framework for K-12 science education practices, crosscutting concepts, and core ideas. In Committee on a Conceptual Framework for New K-12 Science Education Standards, Board on Science Education, Division of Behavioral and Social Science and Education. Washington D.C.: The National Academies Press.

National Science Board, Commission on Precollege Education in Mathematics, Science and Technology (1983). Educating Americans for the $21^{\text {st }}$ Century: A plan of action for improving mathematics, science and technology education for all American elementary and secondary students. Washington, D.C.: National Science Foundation.

NGSS Lead States (2013). Next Generation Science Standards: For States, By States. Washington, DC: The National Academies Press.

Powell, J. C., \& Anderson, R. (2002). Changing teachers' practice: curriculum materials and science education reform in the USA. Studies in Science Education, 37, 107-135.

Quinn, F. (2012). A revolution in mathematics? What really happened a century ago and why it matters today. Notices of the AMS, 59(1), 31-37.

Resnick, L. B. (1987). Education and learning to think. Washington, DC: National Academy Press

Reynante, B. M., Selbach-Allen, M. E., \& Pimentel, D. R. (2020). Exploring the promises and perils of integrated STEM, through disciplinary practices and epistemologies. Science \& Education. Published online. https://doi.org/10. 1007/s11191-020-00121-X.

Ring, E. A., Dare, E. A., Crotty, E. A., \& Roehrig, G. H. (2017). The evolution of teacher conceptions of STEM education throughout an intensive professional development experience. Journal of Science Teacher Education, 28(5), 444-467.

Roehrig, G. H., \& Dewey, J. (2021). STEM integration in middle school life science. In Paper to be presented at the 6th International STEM in Education Conference, Vancouver, CA.

Roth, K. J., Druker, S. L., Garnier, H. E., Lemmens, M., Chen, C., Kawanaka, T., ... Gallimore, R. (2006). Teaching science in five countries: Results from the TIMSS 1999 video study (NCES 2006-011). U.S. Department of Education, National Center for Education Statistics. Washington, DC: U.S. Government Printing Office.

Sadler, P., Coyle, H., \& Schwartz, M. (2000). Engineering competitions in the middle school classroom: Key elements in developing effective design challenges. The Journal of the Learning Sciences, 9, 299-327.

Sanders, M. E. (2009). STEM, STEMeducation, STEMmania. The Technology Teacher, 68(4), 20-26.

Sheppard, S. D., Macantangay, K., Colby, A., \& Sullivan, W. M. (2009). Educating engineers: Designing for the future of the field. San Francisco: Jossey-Bass.

Silk, E. M., Higashi, R., Shoop, R., \& Schunn, C. D. (2010). Designing technology activities that teach mathematics. The Technology Teacher, 69(4), 21-27.

Siregar, N. C., Rosli, R., Maat, S. M., \& Capraro, M. M. (2020). The effect of science, technology, engineering and mathematics (STEM) program on students' achievement in mathematics: A meta-analysis. International Electronic Journal of Mathematics Education, 15(1), Article No: em0549.

Stake, R. E. (1995). The art of case study research. Thousand Oaks: Sage.

Toulmin, C., \& Groome, M. (2007). Building a science, technology, engineering and math agenda. Washington, DC: National Governors Association.

Vasquez, J., Sneider, C., \& Comer, M. (2013). STEM lesson essentials, grades 3-8: integrating science, technology, engineering, and mathematics. Portsmouth: Heinemann.

Walker, W. S. (2017). Integrated STEm or integrated STEM? School Science and Mathematics, 117(6), 225-227.

Walker, W. S., Guzey, S. S., Moore, T. J., \& Sorge, B. H. (2018). Frameworks to develop integrated STEM curricula. K-12 STEM Education, 4(2), 331-339.

Yin, R. K. (2014). Case study research: Design and methods, (5th ed., ). Thousand Oaks: Sage Publishing.

Zhang, D., Orrill, C., \& Campbell, T. (2015). Using the mixture Rasch model to explore knowledge resources students invoke in mathematic and science assessments. School Science and Mathematics, 115(7), 356-365.

\section{Publisher's Note}

Springer Nature remains neutral with regard to jurisdictional claims in published maps and institutional affiliations.

\section{Submit your manuscript to a SpringerOpen ${ }^{\circ}$ journal and benefit from:}

- Convenient online submission

- Rigorous peer review

- Open access: articles freely available online

- High visibility within the field

- Retaining the copyright to your article

Submit your next manuscript at $\boldsymbol{\nabla}$ springeropen.com 